\title{
Juvenile nasopharyngeal angiofibroma: A single institution study
}

\author{
Mistry Rajesh C, Qureshi Sajid S, Gupta Shaikat, Gupta Sameer \\ Department of Head and Neck services, Tata Memorial Hospital. Ernest Borges Road, Parel. Bombay, \\ India
}

Correspondence to: Dr. Rajesh Mistry, E-mail: musica@vsnl.com

\begin{abstract}
BACKGROUND: Juvenile nasopharyngeal angiofibroma (JNA) is a rare tumor of adolescent males and there is a paucity of Indian studies on this subject. AIMS: To present the experience of management of JNA at a single institution. SETTING AND DESIGN: This is a retrospective observational study of patients with JNA who presented at the Tata Memorial Hospital between May 1988 and August 2001. MATERIALS AND METHODS: Thirty-two patients with JNA were treated in the study period. Since the time period was prolonged and diagnostic and therapeutic protocols had undergone many changes, the patients were divided into two groups, namely 1988-1996 and 19972001. The age distribution, disease patterns, management approaches and treatment outcomes of patients in the two groups were recorded. Statistical analyses were done using students 't' test and test for proportion. RESULTS: The mean age at presentation was 16 years and more than $90 \%$ of the patients had Stage III or IV disease. Preoperative embolization was carried out in 19 patients. The surgical approaches used were median maxillectomy, infratemporal fossa, transpalatal, maxillary swing and craniofacial approach. The recurrence rate, complete resection rate and cure rates were $12.5 \%, 41 \%$ and $63 \%$ respectively. CONCLUSION: Surgery is the mainstay of treatment of JNA. Preoperative embolization and newer surgical approaches result in less blood loss and complete resection. Aggressive re-resection should be done for resectable recurrences reserving radiotherapy for unresectable, recurrent/ residual disease.
\end{abstract}

Key Words: Juvenile nasopharyngeal angiofibroma, surgical approach, recurrence, residual disease

\section{Introduction}

Juvenile nasopharyngeal angiofibroma (JNA) is a relatively rare tumor occurring mainly in adolescent boys. It accounts for $0.5 \%$ of all head and neck tumors. ${ }^{[1]}$ The origin of the tumor is from the posterolateral wall of the nasal cavity near the superior margin of the sphenopalatine foramen. ${ }^{[2]}$

Typically, patients present with unilateral nasal obstruction and discharge or epistaxis. As the disease progresses facial deformities, prooptosis, blindness and cranial nerve palsies may occur. ${ }^{[3]}$ The diagnosis of JNA is essentially based on a careful history, and nasal endoscopic examination, supplemented by imaging studies using computed tomogram (CT) and Magnetic Resonance Imaging (MRI). MRI studies are probably more accurate than CT in assessing intracranial extension. ${ }^{[4]}$ Biopsies to establish histological diagnosis are contraindicated and definite diagnosis is established by angiography which also serves as therapy since embolization of the tumor-feeding vessels may be performed at the same sitting. The blood supply of these lesions is primarily from the external carotid artery (ECA) and in some cases from the internal carotid artery (ICA). ${ }^{[5]}$

Surgery is the recommended treatment but with the 
highly vascular nature of the lesion there is a risk of extensive blood loss. Preoperative embolization and new surgical approaches facilitate removal without increasing morbidity. ${ }^{[5-15]}$

We present a review of JNA which were treated at the Tata Memorial Hospital with a focus on the therapeutic approaches, efficacy of preoperative embolization and factors affecting local recurrences and resectability.

\section{Materials and Methods}

This is a retrospective observational study whereby the medical records of 32 patients treated for JNA between May 1988 and August 2001 were reviewed. Since the time period was prolonged and diagnostic and therapeutic protocols had undergone many changes, the patients were divided into two groups, namely 1988-1996 and 1997-2001. Twenty patients were treated between 1988 to 1996 and 12 between 1997 to 2001.

Fourteen patients belonged to the $10-14$ years age group, 15 to the 15-19 years age group, and three patients belonged to the $20+$ years age group. The mean age was 16 years (range 11-35 years). All patients were males.

The tumors were staged according to the criteria laid down by Chandler et $\mathrm{al}^{[1]}$ (Table 1 ). The mean duration of follow-up was 30.3 months (range 6-140 months). Six patients were lost to follow-up (18\%). The age distribution, disease patterns, management approaches and treatment outcomes of patients in the two groups were recorded. Statistical analyses were done using students ' $\mathrm{t}$ ' test and test for proportion. Since this was a retrospective observational study ethical clearance was not sought.

\section{Results}

From 1988 to 2001, 32 patients were treated for JNA at the Tata Memorial Hospital.

\section{Table 1: Staging of juvenile nasopharyngeal angiofibroma according to Chandler et al.}

\begin{tabular}{ll} 
Stage I & Tumor confined to the nasopharynx \\
\hline Stage II & $\begin{array}{l}\text { Tumor extending into the nasal cavity and/or sphenoid } \\
\text { sinus }\end{array}$ \\
\hline Stage III & $\begin{array}{l}\text { Tumor extending into one or more of the following: } \\
\text { antrum, ethmoid sinus, pterygomaxillary and } \\
\text { infratemporal fossae, orbit and/or cheek }\end{array}$ \\
\hline Stage IV & Tumor extending into cranial cavity \\
\hline
\end{tabular}

\section{Pattern of disease}

The stage distribution of the patients is detailed in Table 2 . More than $90 \%$ of the patients presented in Stage III or IV disease, and there was no significant difference in the stage of presentation between the two time periods $(P=0.7)$.

\section{Preoperative embolization}

Pre-operative embolization was done in $19(60 \%)$ patients, including all 12 patients who were treated after 1997. Only seven (39\%) patients underwent preoperative embolization from the 18 patients who were operated between 1988-1996. The blood supply in the 12 patients operated after 1997 was from the branches of both the ICA and ECA in six patients; from the branches of ECA alone in four patients and from the branches of the ICA alone in two patients. Data regarding angiography findings in the seven patients who underwent embolization before 1997 was not available.

\section{Treatment Modalities}

Table 3 outlines the various treatment modalities used by us. Twenty-nine patients were treated with surgery alone and one patient was treated with surgery followed by postop adjuvant radiotherapy (RT) for residual disease near the cavernous sinus. Two patients were treated with RT alone, as they presented with unresectable intracranial residual disease, after having undergone primary surgery elsewhere. None of our patients were given chemotherapy, either primarily or

\begin{tabular}{lccc}
\hline \multicolumn{4}{l}{ Table $2:$} \\
\hline Stage & $1988-1996$ & $1997-2001$ & Total \\
\hline I & $1(5)$ & 0 & $1(3.1)$ \\
\hline II & 0 & $1(8)$ & $1(3.1)$ \\
\hline III & $12(60)$ & $6(50)$ & $18(56.2)$ \\
\hline Total & $7(35)$ & $5(42)$ & $12(37.5)$ \\
\hline
\end{tabular}

Parenthesis are in percentage

Table 3: Treatment modalities used in the Tata Memorial Hospital

\begin{tabular}{lr}
\hline \multicolumn{1}{c}{ Treatment modality } & No. (\%) \\
\hline Surgery only (with preoperative embolization) & $19(59.3)$ \\
\hline Surgery only (without preoperative embolization) & $10(31.2)$ \\
\hline Surgery followed by adjuvant radiotherapy & $1(3.1)$ \\
\hline Adjuvant radiotherapy only (primarily operated elsewhere) & $2(6.2)$ \\
\hline Total & $32(100)$ \\
\hline
\end{tabular}


as adjuvant.

Table 4 demonstrates the various surgical approaches used on the 30 patients who were operated at the Tata Memorial Hospital. Since the year 2000, maxillary swing has been a commonly used approach as it gives superior exposure compared to the other approaches. The patient who underwent a total maxillectomy with orbital exenteration had disease involving the whole of the right antrum and right orbit with loss of vision.

\section{Outcomes}

Between 1988-1996, 7/20 (35\%) patients had a complete resection. Four patients developed local recurrences and were re-operated. They are disease-free at a mean follow-up of three years. All four of these patients had Stage III disease on presentation. Of the $13(65 \%)$ patients in whom residual disease was left behind (two of these were primarily operated elsewhere) seven were re-operated and are disease-free at a mean follow-up of four years and three were radiated and are under observation with static disease after 4 years. Three others are lost to follow-up. Stage IV disease was present in seven and Stage III disease in six of the 13 patients.

Between 1997-2001, 6/12 (50\%) patients had a complete resection. None of them had a recurrence and are disease-free at a mean follow-up of three years. Of these six cases, one was in Stage II and five were in Stage III. Of the six (50\%) patients in whom residual disease was left behind, two patients are under observation for the last two years for static disease and one has had a complete response to adjuvant RT and is disease-free at one year. Three others are lost to followup. Stage IV disease was present in five and Stage III in one patient.

Thus, no patients with Stage IV disease could be fully resected and $61 \%$ of Stage III disease could be completely resected. All patients with Stage I and II disease were completely resected. Also, a lesser proportion of cases done after 1997 had incomplete resections. Complete resections therefore were achieved in $13(41 \%)$ and $19(59 \%)$ had residual disease including the two patients operated outside. The average blood loss in the embolized group was $828 \mathrm{ml}$ (range 535-1570), whereas that in the non-embolized group was $1609 \mathrm{ml}$ (range 610-2320, $P=0.18$ ). The average duration of surgery in the embolized group was $2.9 \mathrm{~h}$ (range 1.8-3.6), whereas that in non-embolized group was 3.5 hours (range 2.2-4.1, $P=0.08$ ).

There were no perioperative or postoperative mortalities or incidences of postoperative hemorrhage. There were eight palatal fistulas, six following the transpalatal approach and two after the maxillary swing. These fistulas were closed within three weeks of the surgery and the two fistulas following maxillary swing needed a palatal obturator. Overall they did not result in any significant morbidity. There was no cerebrospinal leakage in any of the patients. There are no recorded deaths, although six (18\%) patients are lost to followup, all of them with residual unresectable disease. Local recurrence developed in four (12.5\%) patients and all were salvaged. Sixty-five per cent patients are alive without disease, and $15 \%$ alive with disease.

\section{Discussion}

Juvenile nasopharyngeal angiofibroma as the name suggests is the disease of young persons. ${ }^{[2,3]}$ In our series the median age of presentation was 16 years and is comparable to the observations made in the literature. Genetic studies have revealed strong androgen receptor expression in JNA suggesting that JNA is an androgendependent tumor. This could probably explain the predilection for the male sex. ${ }^{[16]}$

Most of the patients in our series (94\%) belonged to Chandler's Stage III and IV which is more than what is

\section{Table 4: Surgical approaches used in the Tata Memorial Hospital}

\begin{tabular}{|c|c|c|c|}
\hline Surgical approach & 1988-1996 & $1997-2001$ & Total \\
\hline Lateral rhinotomy and medial maxillectomy & $9(50)$ & $5(41.6)$ & $14(46.6)$ \\
\hline Lateral rhinotomy and medial maxillectomy combined with transpalatal approach & $4(22.2)$ & 0 & $4(13.3)$ \\
\hline Transpalatal approach only & $2(11.1)$ & $1(8.3)$ & $3(10)$ \\
\hline $\mathrm{ITF}^{*}$ approach combined with transpalatal & $1(5.5)$ & 0 & $1(3.3)$ \\
\hline ITF approach combined with medial maxillectomy & $1(5.5)$ & 0 & $1(3.3)$ \\
\hline Maxillary swing (facial translocation) & 0 & $4(33.3)$ & $4(13.3)$ \\
\hline Craniofacial resection (Combined extracranial-intracranial approach) & $1(5.5)$ & $1(8.3)$ & $2(6.6)$ \\
\hline Total maxillectomy with orbital exenteration & 0 & $1(8.3)$ & $1(3.3)$ \\
\hline Total & $18(100)$ & $12(100)$ & $30(100)$ \\
\hline
\end{tabular}

*Infratemporal fossa; Parenthesis are in percentage. 
reported in western literature. The late presentation can be attributed to the poor health services in the rural areas and peripheral centers.

Data reveal that during the last five years there has been a change in the management of JNA. Improved surgical control rates were largely due to better surgical support with embolization and augmented by the newer surgical approaches and the increasing experience. Preoperative embolization has been noted to reduce intraoperative blood loss. ${ }^{[5,6]}$ In the present series blood loss $(828 \mathrm{ml}$ vs. $1609 \mathrm{ml})$ was almost halved and also the duration of surgery was reduced $(2.9 \mathrm{~h}$ vs. $3.5 \mathrm{~h}$ ) although this was not statistically significant.

Surgery is the recommended treatment for JNA. ${ }^{[2,3]}$ Our standard of care for management of JNA has been surgery and RT is reserved for residual disease after surgery or for palliation of advanced unresectable disease. There are various approaches described in the literature. ${ }^{[7-15]}$ The choice of the approach should be based on the stage and site of the lesion. Since the year 2000 a maxillary swing (facial translocation) approach was more commonly used because of the wider exposure it provides of the nasal cavity, paranasal sinus, pterygopalatine fossa, and cavernous sinus. While its ill effect on facial growth due to extensive soft tissue dissection and multiple osteotomies has been reported in the literature we have not faced this in the limited follow-up that we have. ${ }^{[17]}$ In the recent years much interest has been focused on transnasal endoscopic techniques for resection. ${ }^{[1-14]}$ We have successfully used this in one of our cases recently (not part of this analysis). Endoscopic surgeries permit a minimally invasive resection of the tumor with minimal blood loss and complications. They have also been proposed to reduce recurrences as the finger-like extension can be precisely seen with the endoscopes. ${ }^{[14]}$ The endoscopic approach is mostly used for early stage tumor, although some centers with extensive experience in endoscopic techniques have used them in selected cases of Stage III disease. ${ }^{[12,13]}$ The primary disadvantage of an endoscopic approach is restricted access and difficulty of shifting to an alternative approach if there is excessive bleeding. ${ }^{[14]}$ Moreover, the availability of expensive instrumentation and expertise is a limiting factor in most developing countries.

The treatment of intracranial extension of JNA is controversial. Some authors advocate a combined intracranial and extracranial approach for excision of the tumor. ${ }^{[15]}$ Others believe in radiating these tumors, reserving surgery for recurrences. ${ }^{[18]}$ Some authors advocate resection of the extracranial part and either observation of the intracranial part or radiation of residual disease. ${ }^{[19,20]}$ In our institute surgery was attempted for all JNA with intracranial extension by the cranio-facial approach. It is almost always possible to resect these tumors from below, as the lesion is not infiltrative. JNA has a pushing margin that can cause pressure resorption of the base skull with resultant intracranial extension. However it rarely, if ever, infiltrates the duramater.

The reported recurrence rate following treatment of JNA varies from $0-55 \% .{ }^{[21,22]}$ We had a recurrence rate of $12.5 \%$. All these recurrences occurred in cases operated before 1997, and the recurrence rate post1997 is zero. This we attribute to the improvement in surgical techniques assisted by preop embolization. The high rate of recurrences in JNA following surgery is attributed to the lack of encapsulation of the tumor and its propensity for submucosal spread. The recurrence rate is high once the tumor has extended into the bony confines of the nose, pterygopalatine fossa, and paranasal sinus to infiltrate the soft tissues of the infratemporal fossa (ITF), sphenoid sinus and cavernous sinus, base of pterygoid, base of clivus and foramen lacerum. ${ }^{[4,21,22]}$

Eleven patients were re-operated for recurrent or residual disease and all are disease-free. Four patients were radiated for residual disease and three are under observation for static disease and one patient had a complete response. Thus recurrences and residual disease following surgery tend to benefit from aggressive surgery and/or RT. But some authors feel recurrences should be treated with RT or kept under observation rather than performing extensive surgery. ${ }^{[18]}$ For small intracranial recurrences stereotactic radiosurgery may be an alternative. ${ }^{[23]}$

Goepfert et $\mathrm{al}^{[24]}$ recommend chemotherapy for recurrences if further surgery or RT is not recommended. This includes intracranial extension with involvement of vital structures, tumors which receive their major blood supply from intracranial vessels or which recur after major surgery or RT. We have not used chemotherapy in our patients.

Another treatment option used is hormonal therapy, but there is yet no evidence that estrogen therapy or flutamide reduce tumor progression and there is also a risk of serious side effects including cardiovascular complications and secondary neoplasms in the female genital tract. ${ }^{[25,26]}$ 


\section{Conclusion}

Surgery remains the mainstay of therapy for JNA. Accurate staging, preoperative embolization, and newer surgical approaches like endoscopic excision for limited stage disease and maxillary swing approach for advanced stage disease are associated with better surgical outcome. The high recurrence rate in the present study is a result of advanced stage tumors at presentation. Aggressive re-excision should always be considered for resectable recurrent disease and RT should be reserved for unresectable residual or recurrent disease.

\section{References}

1. Chandler JR, Goulding R, Moskowitz L, Quencer RM. Nasopharyngeal angiofibromas: Staging and management. Ann Otol Rhinol Laryngol 1984;93:322-9.

2. Zito J, Fitzpatrick P, Amedee R. Juvenile nasopharyngeal angiofibroma. La State Med Soc 2001;153:395-8.

3. Yang PW, Sheen TS, Ko JY, Liu HM, Hsu MM. Nasopharyngeal angiofibroma: A reappraisal of clinical features and treatment at National Taiwan University Hospital. J Formos Med Assoc 1998;97:845-9.

4. Lloyd G, Howard D, Phelps P, Cheeseman A, Diver J. Juvenile angiofibroma: Modern imaging and its influence on the surgical treatment of juvenile angiofibroma. J Laryngol Otol 1999;113:43-4.

5. Li JR, Qian J, Shan XZ, Wang L. Evaluation of the effectiveness of preoperative embolization in surgery for nasopharyngeal angiofibroma. Eur Arch Otorhinolaryngol 1998;255:430-2.

6. Moulin G, Chagnaud C, Gras R, Gueguen E, Dessi P, Gaubert JY, et al. Juvenile nasopharyngeal angiofibroma: Comparison of blood loss during removal in embolised group versus non-embolised group. Cardio-vasc Intervent Radiol 1995;18:158-61.

7. Ungkanont K, Byers RM, Weber RS, Callender DL, Wolf PF, Goepfert H. Juvenile nasopharyngeal angiofibroma: An update of therapeutic management. Head Neck 1996;18:60-6.

8. Fagan JJ, Synderman CH. Carran RL, Janecka IP. Nasopharyngeal Angiofibromas: Selecting a surgical approach. Head Neck 1997; 19:391-9.

9. Scholtz AW, Appenroth E, Kammen-Jolly K, Scholtz LU, Thumfart WF. Juvenile Nasopharyngeal Angiofibroma: Management and therapy. Laryngoscope 2001;111:681-7.

10. Zhang M, Garvis W, Linder T, Fisch U. Update on the infratemporal fossa approaches to nasopharyngeal angiofibroma. Laryngoscope 1998;108:1717-23.
11. Wormald PJ, Van Hasselt A. Endoscopic removal of juvenile angiofibromas. Otolaryngol Head Neck Surg 2003;129:684-91.

12. Nicolai P, Berlucchi M, Tomenzoli D, Cappiello J, Trimarchi M, Maroldi R, et al. Endoscopic surgery for juvenile angiofibroma: When and how. Laryngoscope 2003;113:775-82.

13. Mann WJ, Jecker P, Amedee RG. Juvenile angiofibromas: Changing surgical concept over the last 20 years. Laryngoscope 2004; 114:291-3.

14. Onerci TM, Yucel T, Ogretmenoglu O. Endoscopic surgery in treatment of juvenile nasopharyngeal angiofibroma. Int J Pediatr Otorhinolaryngol 2003;67:1219-25.

15. Bales C, Kotapka M, Loevner LA, Al-Rawi M, Weinstein G, Hurst $\mathrm{R}$, et al. Craniofacial resection of advanced juvenile nasopharyngeal angiofibroma. Arch Otolaryngol Head Neck Surg 2002; 128:1071-8.

16. Schick B, Rippel C, Brunner C, Jung V, Plinkert PK, Urbschat S. Numerical sex chromosome aberrations in juvenile angiofibromas: Genetic evidence for an androgen-dependent tumor? Oncol Rep 2003; 10:1251-5.

17. Freihofer HP. The timing of facial osteotomies in children and adolescents. Clin Plast Surg 1982;9:441-4.

18. Kasper ME, Parsons JT, Mancuso AA, Mendenhall WM, Stringer $\mathrm{SP}$, Cassisi NJ, et al. Radiation therapy for juvenile angiofibroma: Evaluation by CT and MRI, analysis of tumor regression, and selection of patients. Int J Radiat Oncol Biol Phys 1993;25:689-94.

19. Dare AO, Gibbons KJ, Proulx GM, Fenstermaker RA. Resection followed by radiosurgery for advanced juvenile nasopharyngeal angiofibroma: Report of two cases. Neurosurgery 2003;52:1207-11.

20. Deguchi K, Fukuiwa T, Saito K, Kurono Y. Application of cyberknife for the treatment of juvenile nasopharyngeal angiofibroma: A case report. Auris Nasus Larynx 2002;29:395-400.

21. McCombe A, Lund VJ, Howard DJ. Recurrence in Juvenile nasopharyngeal angiofibroma. Rhinology 1990;28:97-102.

22. Herman P, Lot G, Chapot R, Salvan D, Huay P. Long term followup of Juvenile nasopharyngeal angiofibroma: Analysis of recurrences. Laryngoscope 1999;109:140-7.

23. Lunsford LD, Kondzioloka D, Bissonette DJ, Maitz AH, Flickenger JC. Stereotactic radiosurgery of brain vascular malformations. Neurosurg Clin North Am 1992;3:79-98.

24. Goepfert H, Cangir A, Lee YY. Chemotherapy for aggressive juvenile nasopharyngeal angiofibroma. Laryngoscope 1985; 111:285-9.

25. Labra A, Chavolla-Magana R, Lopez-Ugalde A, Alanis-Calderon J, Huerta-Delgado A. Flutamide as a preoperative treatment in juvenile angiofibroma (JA) with intracranial invasion: Report of 7 cases. Otolaryngol Head Neck Surg 2004;130:466-9.

26. Gatalica Z. Immunohistochemical analysis of steroid hormone receptors in nasopharyngeal angiofibromas. Cancer Lett 1998; 127:89-93. 